\title{
Different types of oestrous cycle in two closely related South American rodents (Cavia aperea and Galea musteloides) with different social and mating systems
}

\author{
C. Touma ${ }^{1}$, R. Palme ${ }^{2}$ and N. Sachser ${ }^{1}$ \\ ${ }^{1}$ Institute of Neuro and Behavioural Biology, Department of Behavioural Biology, \\ University of Münster, Badestrasse 9, D-48149 Münster, Germany; and \\ ${ }^{2}$ Institute of Biochemistry and Ludwig Boltzmann Institute for Veterinary Endocrinology, \\ University of Veterinary Medicine Vienna, Veterinärplatz 1, A-1210 Vienna, Austria
}

A comparative approach was used to investigate two closely related South American rodent species: the wild cavy (Cavia aperea) and the yellow-toothed cavy (Galea musteloides). These species of wild guinea-pig inhabit different habitats and show divergent social and mating systems. Cavia have a polygynous mating system, whereas in Galea promiscuous mating occurs. These observations correspond to functional variations in sperm characteristics, which might be interpreted as adaptations to different reproductive patterns in the females of both species. Twenty-two female $C$. aperea and $G$. musteloides (11 of each species) were investigated to elucidate differences in the characteristics of the oestrous cycles. The experimental design consisted of three stages, in which the degree of contact between the sexes was successively changed. During these stages, the reproductive cycle of the

\section{Introduction}

In mammals, a wide variety of reproductive patterns has been observed (Weir and Rowlands, 1973; Bronson, 1985). Oestrous cycles can be classified by three characteristics: oestrus (behavioural receptivity), ovulation and corpus luteum activity. In most mammals, behavioural receptivity can be observed in periodic cycles (for example, in guineapigs, mice, many ungulate species: Conaway, 1971; Nelson, 2000), but in other animals (for example, in many species of vole, grey short-tailed opossums, musk shrews: Hasler and Conaway, 1973; Carter et al., 1980; Fadem, 1987; Rissman et al., 1988; Hinds et al., 1992; Taylor et al., 1992) behavioural receptivity is induced by stimuli from the male. During oestrus, ovulation can occur spontaneously, as found in most mammalian species (for example, in guinea-pigs, mice, dogs, most primate species: Conaway, 1971; Nelson, 2000), or it can be induced by specific stimuli, for example, from copulation (for example, in minks, cats, voles, brush-tailed bettong: Gray et al., 1974;

Email: touma@uni-muenster.de females was monitored by examining the condition of the vaginal closure membrane, analysing vaginal smears and determining serum concentrations of oestrogens and progesterone. The results revealed different types of oestrous cycle in the two species. Female $C$. aperea showed periodical cycles with spontaneously occurring oestrous periods, ovulation and corpus luteum activity. In contrast, in female $G$. musteloides, oestrus was exclusively induced by the presence of a male. However, after the induction of oestrus, ovulation and corpus luteum activity occurred spontaneously without stimuli from copulation. To date this type of oestrous cycle has not been described for any other mammalian species. Thus, these data indicate that differences in the reproductive patterns of the females may have shaped the evolution of different sperm characteristics in the males.

Wildt et al., 1981; Sundquist et al., 1989; Hinds and Smith, 1992). After ovulation, in general, a functional corpus luteum develops spontaneously (for example, in guineapigs, most primate and ungulate species: Conaway, 1971; Nelson, 2000). However, in some species development of a functional corpus luteum does not occur without stimuli from copulation and, therefore, oestrus returns within a few days (for example, in mice, rats, hamsters: Conaway, 1971; Nelson, 2000). Thus, all three characteristics of the oestrous cycle, behavioural receptivity, ovulation and corpus luteum activity, can occur spontaneously or can be induced by external stimuli. It has been shown that many factors can influence the reproductive cycle and that there are no discrete categories: induced and spontaneous cycles are extremes of a continuum. The functional significance of these different reproductive patterns has not been elucidated. However, it is likely that these differences are adaptations to the environmental conditions a species inhabits (Conaway, 1971; Weir and Rowlands, 1973; Clutton-Brock and Harvey, 1978; Bronson, 1985).

In the present study, a comparative approach was used to investigate two closely related species of South American rodent belonging to the same subfamily (Caviinae): the wild cavy (Cavia aperea; Erxleben, 1777; the wild ancestor of the 
domestic guinea-pig) and the yellow-toothed cavy (Galea musteloides; Meyen, 1833). C. aperea is a herbivore that lives in groups and is found in dense grassland habitats from southern Colombia to Brazil to Argentina (Rood, 1972; Redford and Eisenberg, 1992). The distribution of $G$. musteloides extends from southern Peru into Chile and Argentina where it inhabits savannas and bushland (Rood, 1972; Redford and Eisenberg, 1992). Although both species live in groups in the wild, studies under semi-natural and laboratory conditions reveal completely different social and mating systems (Rood, 1972; Sachser, 1998; Sachser et al., 1999). Adult male $C$. aperea are highly incompatible in the presence of females, whereas female $C$. aperea organize themselves into linear dominance hierarchies. As a result, there is a polygynous mating system in this species (Rood, 1972; Sachser et al., 1999). However, G. musteloides is much more tolerant and can be kept in large mixed-sex colonies, in which a promiscuous mating system is observed (Rood, 1972; Schwarz-Weig and Sachser, 1996).

Little is known about the reproductive physiology of these wild guinea-pigs. However, a comparison of sperm motility and sperm morphology in Cavia and Galea revealed interesting results, indicating an adaptation of the reproductive characteristics of males to differences in the reproductive patterns of the females (Cooper et al., 2000). This conclusion is based on studies in which different types of oestrous cycle were observed in these two species. Rood and Weir (1970) suggested that female C. aperea have spontaneous oestrous cycles similar to those of the domestic guinea-pig. In contrast, in female G. musteloides, spontaneous oestrous cycles were not observed, but receptivity could be induced by the presence of a male conspecific (Rood and Weir, 1970; Weir, 1971, 1973; Norris and Adams, 1979). However, these studies were carried out on only a few animals and therefore it may not be possible to make reliable conclusions with regards to details of the reproductive cycles of these cavies.

The aim of this study was to investigate the characteristics of the oestrous cycle in $C$. aperea and $G$. musteloides. It was hypothesized that two species with different social and mating systems and different sperm characteristics would have different types of oestrous cycle.

\section{Materials and Methods}

\section{Animals and general housing conditions}

The animals used in this study were derived from breeding stocks established at the Department of Behavioural Biology, University of Münster. The wild cavies (C. aperea; Erxleben, 1777) were descended from feral animals trapped in the province of Buenos Aires, Argentina in 1995. The yellow-toothed cavies (G. musteloides; Meyen, 1833) were descendants of animals obtained from different institutions between 1994 and 1996 (Keil and Sachser, 1998). Both species were maintained under standard laboratory conditions in indoor enclosures $(12 \mathrm{~h}$ light:12 h dark, lights on at 07:00 h, $20 \pm 2{ }^{\circ} \mathrm{C}$, humidity $55 \pm 10 \%$ ). All animals were marked individually by cutting or bleaching their fur. Commercial guinea-pig diet (Altromin $\mathrm{GmbH}$, Lage), flaked oats and water were available ad libitum. This diet was supplemented regularly with vegetables and hay.

\section{Experimental design}

Oestrous cycles of 22 adult females (11 of each species) were monitored. Within each species, six animals were treated as experimental females and five as control females (experimental + control females $=$ test females).

An experiment was performed consisting of three successive stages (1,2 and 3), during which the degree of contact between the sexes was changed (see Experimental stages), to study the differences in characteristics of the oestrous cycle in female $C$. aperea and $G$. musteloides. During all three stages, the reproductive pattern of the females was monitored by examining the condition of the vaginal closure membrane, by analysing vaginal smears and, during stage 2 and 3, by determining serum concentrations of oestrogens and progesterone.

\section{Sampling procedures}

Vaginal closure membrane. In caviomorph rodents, the females of nearly all species have a vaginal closure membrane (VCM), which is perforated only at oestrus and parturition (Rood and Weir, 1970; Weir, 1974). In female C. aperea and G. musteloides, the duration of perforation at oestrus varies with the individual, but usually it can be recognized for 3-5 days (Rood and Weir, 1970; Weir, 1974; C. Touma, unpublished). Thus, in these species, the condition of the VCM can be used as an external indication of oestrus. The following six categories were defined to assess the condition of the VCM: closed (0), punctured (1), $25 \%$ open (2), $50 \%$ open (3), $75 \%$ open (4) and completely open (5). The duration of the oestrous cycle in a test female was calculated by counting the number of days between two successive spontaneous vaginal openings (minimum category $25 \%$ open).

Vaginal smears. The cell composition of the vaginal epithelium was assessed by analysing vaginal smears (first described for guinea-pigs by Stockard and Papanicolaou in 1917) to monitor 'vaginal oestrus' in the experimental females. Vaginal smears were obtained by lavage using an isotonic salt solution (as first described by Selle in 1922) and were examined using a microscope shortly after collection $(\times 125)$. The types of cell present and their relative incidence were assessed on a scale of 0 to 5, taking into account leucocytes, parabasal cells, early intermediate cells, late intermediate cells, and superficial cells = cornified cells. The appearance and quantity of types of cell were used to determine 'vaginal oestrus' according to the stages described in published studies (for example, see Stockard and Papanicolaou, 1917; Selle, 1922; Young, 1937). 
Blood sampling and hormone determinations. Blood samples $(0.3-0.8 \mathrm{ml})$ were collected during each sampling procedure, by puncturing the marginal ear vessels of each animal (for further details, see Sachser and Pröve, 1984). The blood samples were collected in heparinized capillary tubes, separated by centrifugation ( $160 \mathrm{~g}$ for $5 \mathrm{~min}$ ) and the plasma was frozen $\left(-30^{\circ} \mathrm{C}\right)$ until analysis. Serum concentrations of oestrogens and progesterone were determined by enzymeimmunoassays. Before enzymeimmunoassay analysis, plasma $(0.1-0.2 \mathrm{ml})$ was extracted with diethyl ether $(5 \mathrm{ml})$. The antisera used in the assays crossreacted with relevant steroids (Steraloids, Wilton, $\mathrm{NH}$ ) as follows: (i) oestrogen antiserum: oestrone (100\%), oestradiol-17 $\alpha(19 \%)$, oestradiol (70\%), oestriol (129\%), 1,3,5(10),7-estratetraen3,17ß-diol (20\%), 1,3,5(10),7-estratetraen-3-ol-17-one (87\%); (ii) progesterone antiserum: progesterone (100\%), 4-pregnen$3 \beta$-ol-20-one $(26 \%), 4$-pregnen-3 $\alpha$-ol-20-one $(8 \%), 5 \alpha$ -

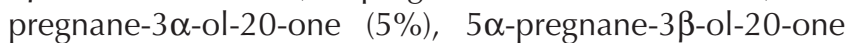
(18\%), 5 $\alpha$-pregnane-3,20-dione (40\%), 5 $\beta$-pregnene-3 $\alpha$-ol-

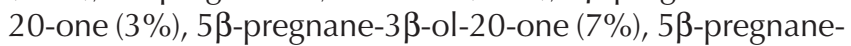
3,20 -dione $(71 \%)$, 5-pregnane-3 $\beta$-ol-20-one (29\%). All other steroids tested crossreacted $<1 \%$. For details of the assay procedures, see Palme and Möstl (1994) and Schwarzenberger et al. (1996). The inter- and intra-assay coefficients of variation were 12.3 and $14.3 \%$ respectively, for the oestrogen assay, and $9.4 \%$ and $11.5 \%$ respectively, for the progesterone assay.

\section{Experimental stages}

Stage 1 - mating phase. Twenty-two non-pregnant test females were housed individually with an adult male conspecific in $0.5 \mathrm{~m}^{2}$ enclosures. The interval from pairing to the first complete vaginal opening (expected day of copulation and beginning of pregnancy) was measured each day by examining the VCM. Up to day 15 of pregnancy, no further handling was performed and the test females remained in the same enclosure as the male.

Stage 2 - separation phase. At day 15 of pregnancy, females were separated from the males and were transferred to another housing room. After day 15, each test female was housed with a small sub-adult female conspecific (known as 'social females') in a $0.5 \mathrm{~m}^{2}$ enclosure to avoid isolationinduced stress. The enclosures were located in a housing room where no males were present, to exclude male influences on the oestrous cycle of the females. Throughout the remainder of pregnancy and for the next 30 days, the test females were kept in this housing room.

Starting with the day of parturition, the reproductive pattern of the experimental female was monitored by the following procedure: the condition of the VCM was examined at 3 day intervals and blood samples were collected at 6 day intervals. On the day the VCM was found to be perforated (25\% open), a vaginal smear and blood sample were taken immediately. This procedure was repeated on the subsequent day. On day 3 of the observed vaginal opening, only a vaginal smear was obtained. The handling subsequently followed the procedure described of examining the VCM at 3 day intervals and collecting blood samples at 6 day intervals, and continued until the end of the separation phase (minimum of 30 days after parturition). Thus, the sampling procedure was adapted to the oestrous cycle of each experimental female. This sampling procedure was designed to monitor the oestrous cycle in as much detail as possible, while minimizing the effects of the invasive sampling procedures. Previous studies indicate that no vaginal opening occurs in female G. musteloides when isolated from males (Rood and Weir, 1970; Weir, 1971, 1973). Pairs of one Cavia and one Galea female were matched to achieve a comparable handling procedure for both species during the separation phase. An experimental female $G$. musteloides was treated in the same way at times corresponding to the experimental female $C$. aperea.

The handling procedure for the control females was less invasive to enable identification of possible effects of the sampling procedures on the oestrous cycles of the experimental females. The reproductive cycles of the control females were monitored only by examining the condition of the VCM at 3 day intervals during the entire 30 day period of the separation phase, starting at the day of parturition.

The offspring of all test females were kept with their mothers for $15 \pm 1$ days, after which they were removed from the housing room.

Two female C. aperea (one experimental and one control female) had to be excluded from the experiment because of complications during pregnancy. In total, nine female C. aperea were investigated in stages 2 and 3 .

Stage 3 - mesh-contact phase. At the end of stage 2, the test females were transferred with their social females to enclosures located in another housing room. During this stage, it was possible for the test females to hear, smell and see a mature male conspecific, but physical contact was prevented. Physical separation was achieved by using a wire mesh partition to separate the enclosure housing the females from the adjoining enclosure in which the male was housed (enclosure size: $0.5 \mathrm{~m}^{2}$ each).

For the experimental females, the condition of the VCM was examined each day and blood samples were collected at 6 day intervals starting at the day of transfer to stage 3 . As in stage 2, a blood sample and a vaginal smear were obtained immediately on the day the VCM was found to be perforated. The same procedures were performed on the subsequent day and an additional vaginal smear was obtained on day 3 of vaginal opening. Subsequently, the experimental females were treated in the same way as in the separation phase (examining the VCM at 3 day intervals and collecting blood samples at 6 day intervals). If a second vaginal opening was observed within the 30 days of the mesh-contact phase, the same procedures as described above were performed. Thus the sampling procedure was adjusted to the oestrous cycle of each experimental female C. aperea and G. musteloides. 
Treatment of the control females during the meshcontact phase did not differ from that performed in the separation phase. The condition of the VCM was examined at 3 day intervals for an additional 30 days without any further handling.

\section{Statistical analyses}

Since the data were not normally distributed and the sample size was relatively small, the data were analysed by non-parametrical statistics. Two independent samples were compared using the Fisher's test or the Mann-Whitney $U$ test (both two-tailed). An ANOVA on ranks was used to evaluate differences between more than two dependent samples. Differences were considered significant at $P<0.05$.

\section{Results}

\section{Stage 1 - mating phase}

Significant differences between female $C$. aperea and G. musteloides were found in the interval from pairing with a male to the first vaginal opening (Mann-Whitney $U$ test; $U=3 ; P<0.001$; Fig. 1a). In female $C$. aperea, the VCM was found to be perforated within a range of 3-13 days whereas, in all female G. musteloides, a complete vaginal opening was observed after 1-3 days of contact with a male.

\section{Stage 2 - separation phase}

On the day of parturition (day 0 of stage 2), the VCM of all test females was completely open, and closed within a few days. In eight of nine female $C$. aperea, a second spontaneous vaginal opening was observed (Fig. 2h) between day 15 and day 24 of stage 2 (median oestrous cycle duration: 21 days). This observation was in contrast to findings for all female G. musteloides, in which no spontaneous vaginal openings were detected for the rest of the separation phase (Fig. 3h), leading to a significant difference between the two species (Fisher's test; $P<0.001)$.

The vaginal smears also revealed significant differences between female $C$. aperea and G. musteloides (Fisher's test; $P<0.01)$. In all female $C$. aperea in which vaginal smears were obtained during the days of vaginal opening, the cytological findings confirmed a 'vaginal oestrus' with the typical distributions of different types of cell: superficial cells and late intermediate cells dominated the smears during the first days of vaginal opening and these cells subsequently decreased, whereas the number of parabasal cells was found to increase (ANOVA on ranks $\chi_{r}^{2}=6.5-7.1$; $\mathrm{df}=2$; all $P<0.05 ; n_{\text {Cavia }}=4$; see Fig. $\left.2 \mathrm{e}, \mathrm{f}\right)$. In contrast, the vaginal smear of the matched female $G$. musteloides did not show signs of 'vaginal oestrus' (Fig. 3e,f). In these smears, leucocytes were dominant and a few parabasal cells and early intermediate cells were present, whereas significantly
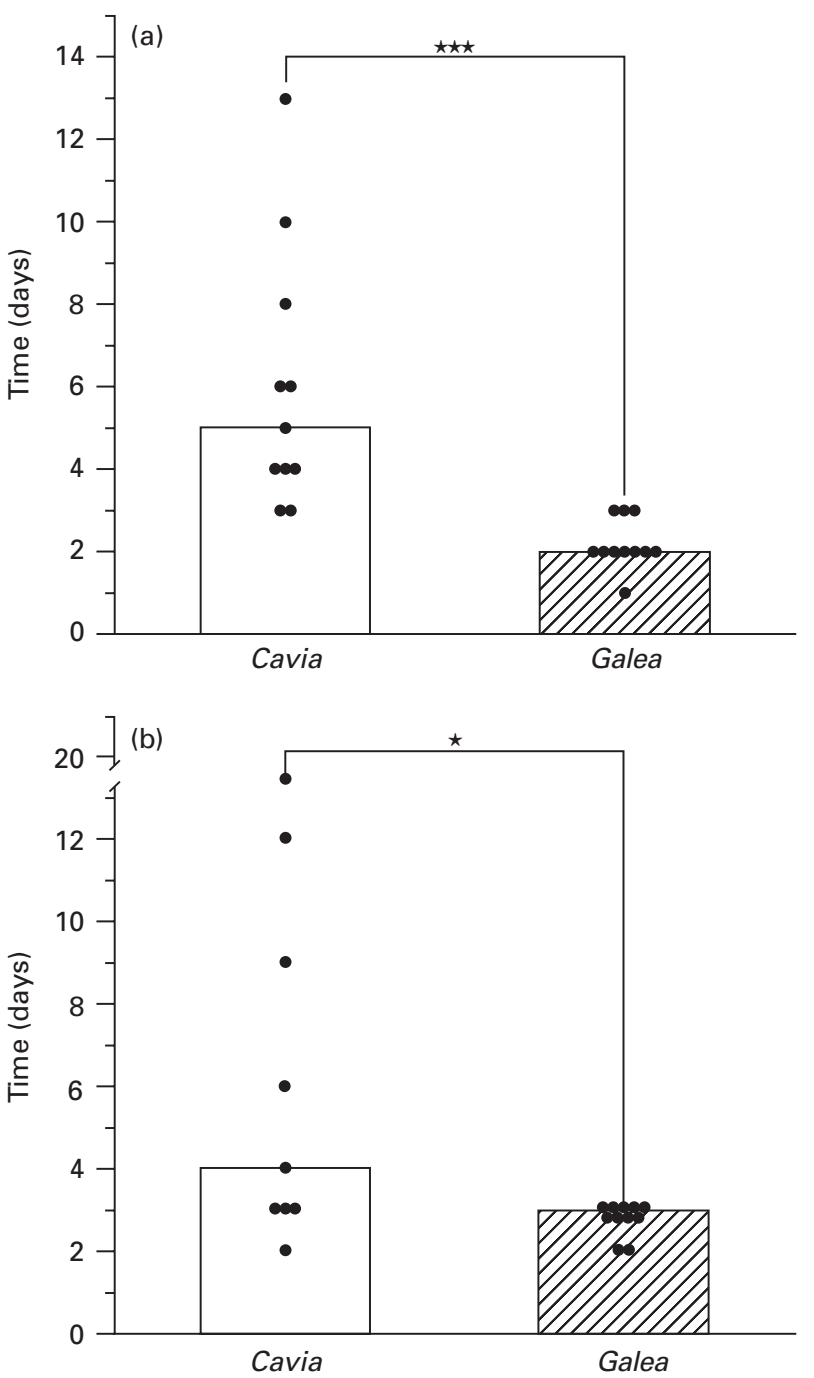

Fig. 1. (a) The time from pairing with a male to the first vaginal opening in test females Cavia aperea $(n=11)$ and Galea musteloides $(n=11)$ during the mating phase. (b) Time from contact with a male conspecific through a wire mesh partition to the first vaginal opening in test females $C$. aperea $(n=9)$ and $G$. musteloides $(n=11)$ during the mesh-contact phase. Medians and individual values are given. Mann-Whitney $U$ test (two-tailed), (a) $U=3$; ${ }^{* * *} P<0.001$, (b) $U=23.5$; ${ }^{*} P<0.05$.

fewer superficial cells and late intermediate cells were found on all 3 days of the artificial vaginal opening (Mann-Whitney $U$ test; $n_{\text {Cavia }}=4, n_{\text {Galea }}=5$; all $U=0$; all $P<0.05)$.

Although individual differences were obvious among the experimental females, the patterns of serum oestrogen concentrations during the separation phase differed principally between female C. aperea and G. musteloides. In the experimental female $C$. aperea, oestrogen concentrations decreased rapidly after parturition to very low concentrations (median: $10.1 \mathrm{pmol} \mathrm{I}^{-1}$; individual 

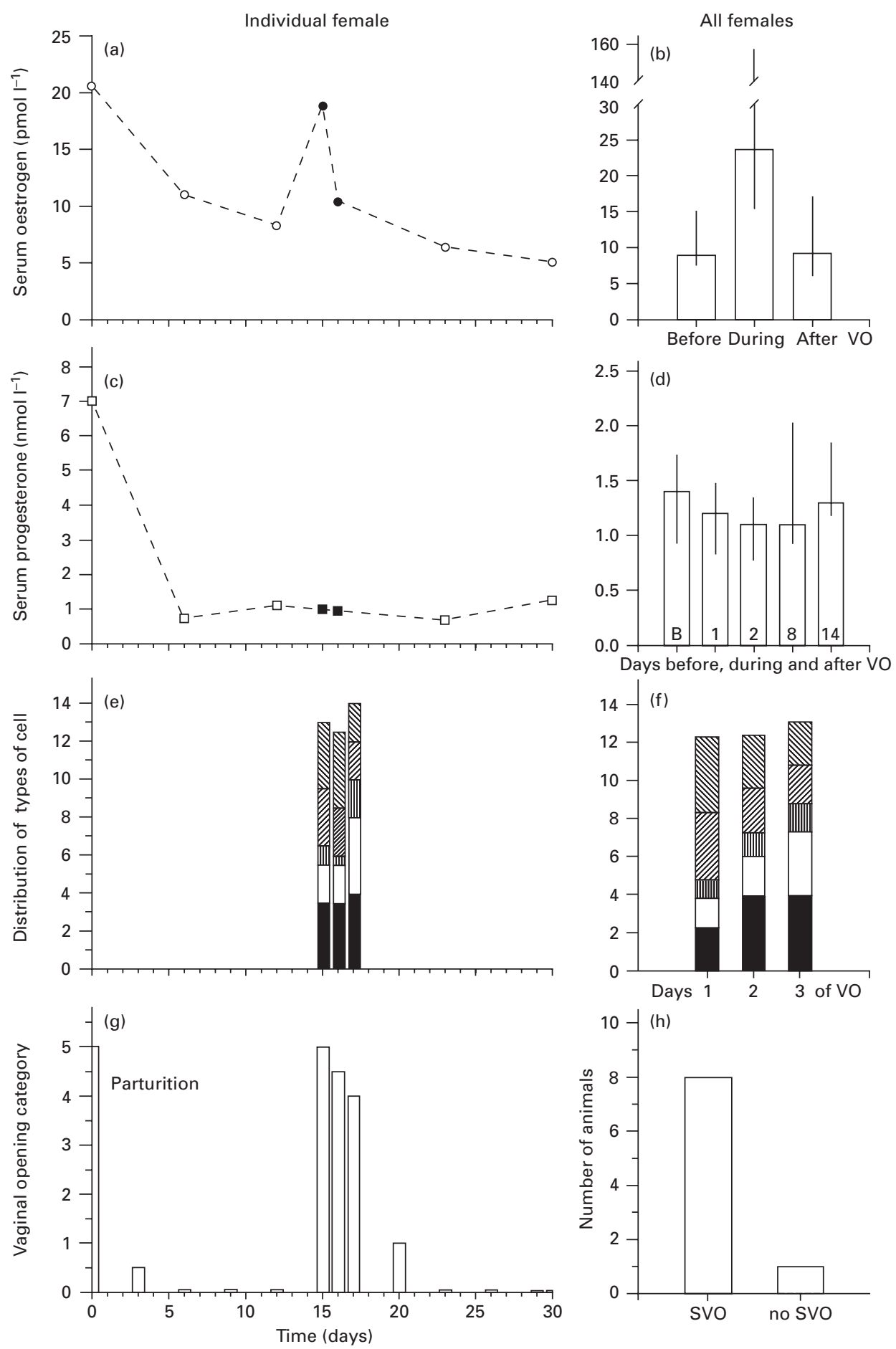

Fig. 2. Experimental data from female Cavia aperea during the separation phase. On the left-hand side concentrations of oestrogens (a) and progesterone (c), the distribution of different types of cell (leucocytes $\square$, parabasal cells $\square$, early intermediate cells 四, late intermediate cells 面, superficial cells $\mathbb{\mathbb { N }}$ ) in the vaginal smears (e) and the condition of the vaginal closure membrane (g) are plotted versus time (days) during the separation phase for a representative female $C$. aperea (individual values are connected to illustrate the patterns of hormone concentrations; filled symbols indicate the days of vaginal opening). On the right-hand side data are given for all female $C$. aperea. Concentrations of oestrogens (b) and progesterone (d) on the days before (B), during (days 1 and 2) and after (day 8 and day 14 ) vaginal opening $(\mathrm{VO})$ are plotted as medians with interquartiles. (f) The median distribution of different types of cell in the vaginal smears during the days of vaginal opening. (h) The number of animals in which a second spontaneous vaginal opening (SVO) was observed during the separation phase. 

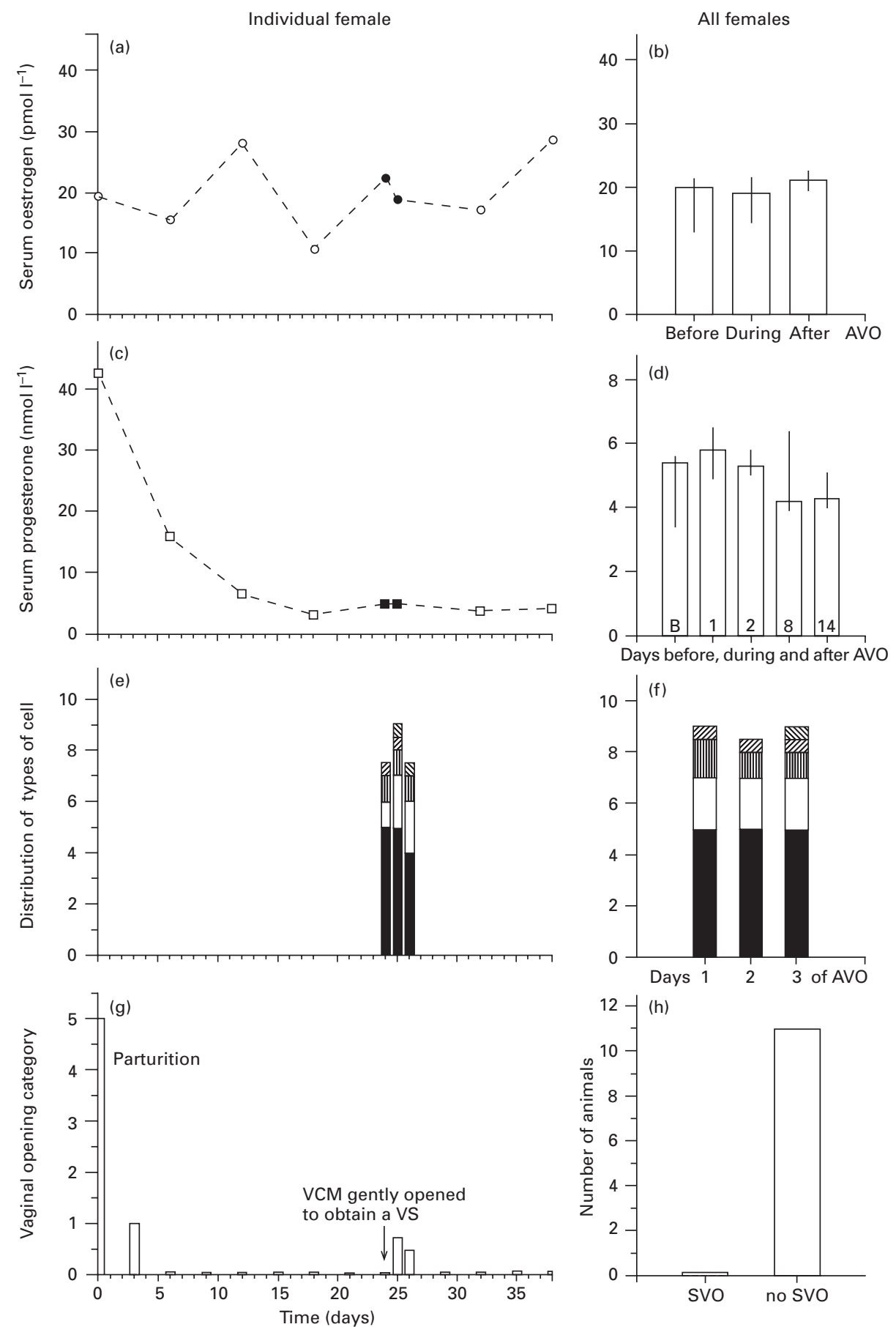

Fig. 3. Experimental data from female Galea musteloides during the separation phase. On the left-hand side concentrations of oestrogens (a) and progesterone (c), the distribution of different

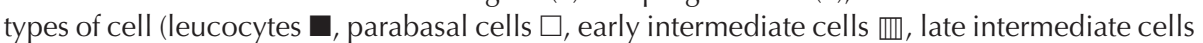
道, superficial cells $\mathbb{\mathbb { N }}$ ) in the vaginal smears (e) and the condition of the vaginal closure membrane (VCM) (g) are plotted versus time during the separation phase for a representative female G. musteloides (individual values are connected to illustrate the patterns of hormone concentrations; filled symbols indicate the days when the vaginal closure membrane was slightly opened to obtain a vaginal smear). On the right-hand side data are given for all female G. musteloides. Concentrations of oestrogens (b) and progesterone (d) on days before (B), during (days 1 and 2) and after (day 8 and day 14) the artificial vaginal opening (AVO) are plotted as medians with interquartiles. (f) The median distribution of different types of cell in the vaginal smears during the days of artificial vaginal opening. (h) The number of animals in which a second spontaneous vaginal opening (SVO) was observed during the separation phase. 
concentrations: $4.8-28.5 \mathrm{pmol}^{-1}$ ) and remained at these basal concentrations until the end of the separation phase. However, marked increases in oestrogen concentrations were measured on the first day of vaginal opening, but were not observed on the subsequent day. Since this oestrogen peak was detected in only two of four experimental females, ANOVA on ranks analysing all females did not reveal a significant difference (Fig. 2a,b). In comparison with female C. aperea, the patterns of oestrogen concentrations in the experimental female G. musteloides were more heterogeneous during the separation phase. In three of six experimental females, the hormone concentrations were low and relatively constant (median: 15.6 pmol $\mathrm{I}^{-1}$; individual concentrations: $12.2-19.6 \mathrm{pmol} \mathrm{I}^{-1}$ ) throughout the entire experimental stage, whereas variations were observed in the other females (Fig. 3a,b).

The patterns of serum progesterone concentrations were comparable in experimental females of both species. On the day of parturition, all females had high progesterone concentrations, which decreased to basal values within the next 6 days (medians: Cavia $1.6 \mathrm{nmol} \mathrm{I-1}$; Galea $5.6 \mathrm{nmol}$ $\mathrm{I}^{-1}$ ). For the rest of the separation phase, hormone concentrations remained at these values with little fluctuation (Figs 2c,d and 3c,d).

\section{Stage 3-mesh-contact phase}

In contrast to the situation in the separation phase, in the mesh-contact phase, females now had acoustic, visual and olfactory contact with a male conspecific, which led to different effects on the reproductive cycle of each species.

A comparison of the interval to the first vaginal opening in the mesh-contact phase revealed significant differences between the species (Mann-Whitney $U$ test; $U=23.5$; $P<$ 0.05; Fig. 1b). In the female $C$. aperea, a perforated VCM was observed during a wider range of days (2-20 days) after the beginning of the experimental mesh-contact phase. In contrast, all female G. musteloides showed a complete vaginal opening within 2 or 3 days of mesh-contact with a male.

A further difference in the reproductive pattern of the two species was also observed. Nearly all female C. aperea (eight of nine) showed a second or a third vaginal opening during the course of the mesh-contact phase (Fig. 4h). The intervals between two successive vaginal openings revealed a median oestrous cycle duration of about 15 days (range 12-20 days) for the female $C$. aperea. However, in most female G. musteloides (8 of 11) no cyclic pattern was observed and the VCM remained closed for the rest of the mesh-contact phase (Fig. 5h), leading to a significant difference between the two species (Fisher's test; $P<0.01$ ).

During the periods of vaginal opening, the vaginal smears showed comparable cytological findings in female C. aperea and G. musteloides, and confirmed 'vaginal oestrus' in both species. During the first days of vaginal opening, a dominance of superficial cells and late intermediate cells was observed in the vaginal smears, shifting rapidly to a predominance of parabasal cells and early intermediate cells on the subsequent days (ANOVA on ranks $\chi_{\mathrm{r}}^{2}=7.9-12.0 ; \mathrm{df}=2 ;$ all $0.001<P<0.05 ; n_{\text {Cavia }}=5$; $n_{\text {Galea }}=6$; see Figs $4 \mathrm{e}, \mathrm{f}$ and $\left.5 \mathrm{e}, \mathrm{f}\right)$. In addition, in most cases, the number of leucocytes decreased in the vaginal smear on one of the first days of the vaginal opening. Subsequently, a marked invasion of leucocytes was observed on the next day accompanied by an increase in parabasal cells and early intermediate cells (ANOVA on ranks $\chi_{r}^{2}=7.6-9.8 ; \mathrm{df}$ $=2 ;$ all $0.01<P<0.05 ; n_{\text {Cavia }}=5 ; n_{\text {Galea }}=6$; see Figs $4 \mathrm{e}, \mathrm{f}$ and $5 e, f)$.

As in the separation phase, concentrations of oestrogens and progesterone measured during the mesh-contact phase also showed individual differences among the experimental females. In contrast, hormone concentrations revealed similar patterns in female C. aperea and G. musteloides. In both species, oestrogen concentrations increased markedly on day 1 or day 2 of vaginal opening and decreased rapidly to basal concentrations on the subsequent day (Figs $4 a, b$ and $5 a, b)$. This pattern was detected in six of nine vaginal openings observed in the five experimental female $C$. aperea (ANOVA on ranks $\chi_{\mathrm{r}}^{2}=7.6 ; \mathrm{df}=2 ; P<0.05 ; n_{\text {Cavia }}=5$; Fig. $4 \mathrm{~b})$ and in three vaginal openings of the six experimental female G. musteloides (Fig. 5b). Only slightly increased oestrogen concentrations were measured in the other cases, resulting in a non-significant variation when all experimental females were considered. As in the separation phase, during periods when the VCM was closed, oestrogen concentrations were generally low in all experimental females.

Progesterone concentrations also showed comparable patterns in both species, but were different from those observed in the separation phase. During the days of vaginal opening, basal progesterone concentrations were measured. However, after 8 days, serum progesterone concentrations increased in all experimental female C. aperea (median: 7.1 nmol I-1; ANOVA on ranks $\chi_{r}^{2}=18.3$; $\mathrm{df}=5 ; P<0.01 ; n_{\text {Cavia }}=5 ;$ Fig. $4 \mathrm{c}, \mathrm{d}$ ) and then decreased slowly to former concentrations within 6-12 days (median: $1.2 \mathrm{nmol} \mathrm{I}^{-1}$ ). Shortly after reaching the individual basal concentrations, the next vaginal opening was observed and progesterone concentrations started to increase in these female $C$. aperea. In the experimental female G. musteloides, similar increases of serum progesterone were measured 8 days after the observed vaginal opening (median: $58.6 \mathrm{nmol} \mathrm{I}^{-1}$; ANOVA on ranks $\chi_{\mathrm{r}}^{2}=25.4$; $\mathrm{df}=5 ; P<0.001 ; n_{\text {Galea }}=6$; see Fig. $5 \mathrm{c}, \mathrm{d}$ ). Subsequently progesterone concentrations also decreased to individual basal concentrations (median: $9.4 \mathrm{nmol} \mathrm{I}^{-1}$ ), but at a later stage than in the female $C$. aperea (within 18 days at the end of the mesh-contact phase).

\section{Discussion}

The results from the present study revealed marked differences in the characteristics of the oestrous cycles in female C. aperea and G. musteloides. Major differences were observed in all three experimental stages. 

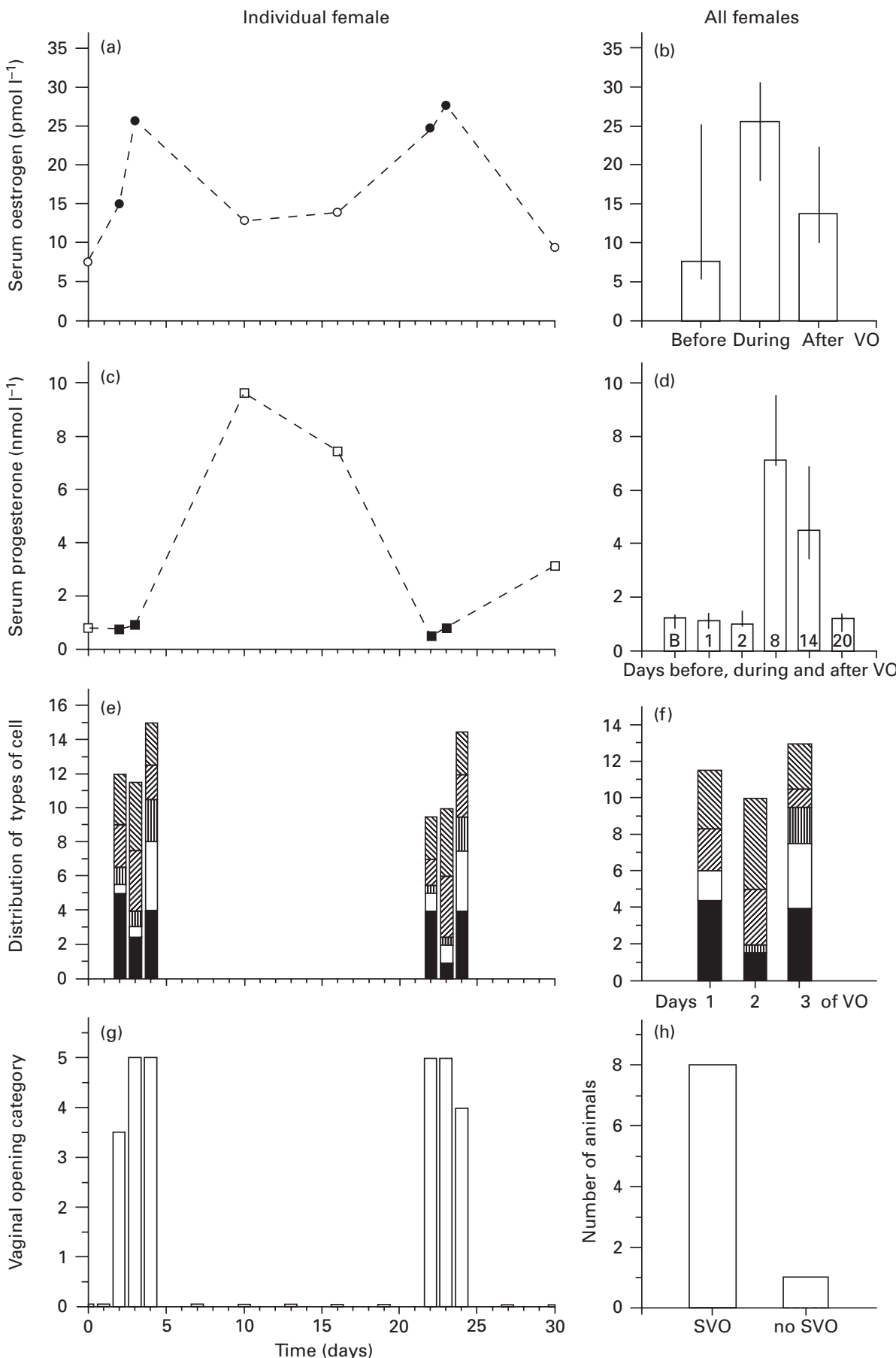

Fig. 4. Experimental data from female Cavia aperea during the mesh-contact phase. On the left-hand side concentrations of oestrogens (a) and progesterone (c), the distribution of different types of cell (leucocytes $\mathbf{\square}$, parabasal cells $\square$, early intermediate cells 四, late intermediate cells $\mathbb{R}$, superficial cells $\mathbb{\mathbb { N }}$ ) in the vaginal smears (e) and the condition of the vaginal closure membrane $(\mathrm{g})$ are plotted versus time during the mesh-contact phase for a representative female $C$. aperea (individual values are connected to illustrate the patterns of hormone concentrations; filled symbols indicate the days of vaginal opening). On the right-hand side data are given for all female $C$. aperea. Concentrations of oestrogens (b) and progesterone (d) on days before (B), during (days 1 and 2) and after (days 8, 14 and 20) the first vaginal opening (VO) are plotted as medians with interquartiles. $(\mathrm{f})$ The median distribution of different types of cell in the vaginal smears during the days of the first vaginal opening. (h) The number of animals in which a second spontaneous vaginal opening (SVO) was observed during the meshcontact phase. 

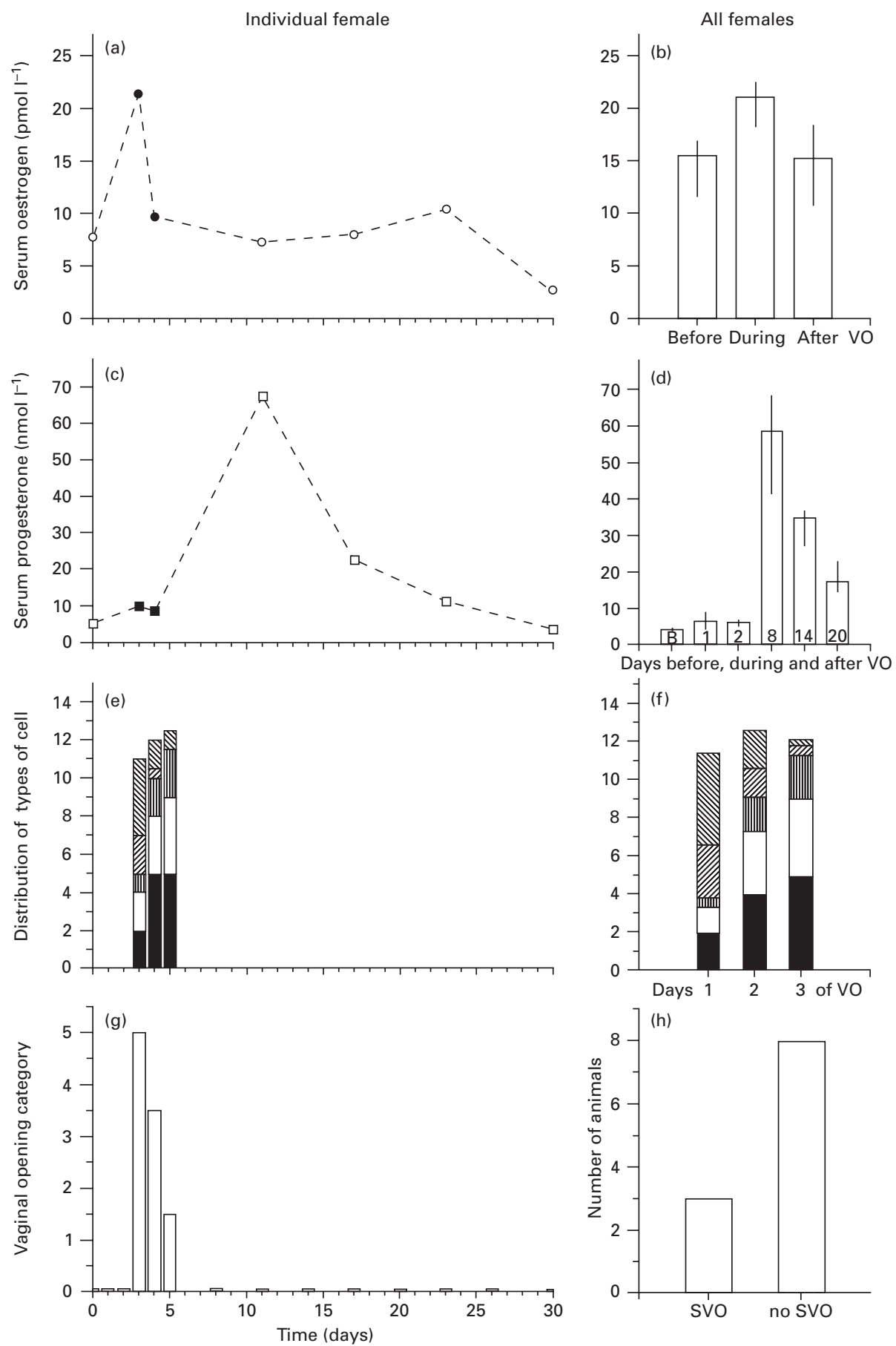

Fig. 5. Experimental data from female Galea musteloides during the mesh-contact phase. On the left-hand side concentrations of oestrogens (a) and progesterone (c), the distribution of different types of cell (leucocytes $\mathbf{\square}$, parabasal cells $\square$, early intermediate cells 四, late intermediate cells 着, superficial cells $\mathbb{Q}$ ) in the vaginal smears (e) and the condition of the vaginal closure membrane $(\mathrm{g})$ are plotted versus time during the mesh-contact phase for a representative female G. musteloides (individual values are connected to illustrate the patterns of hormone concentrations; filled symbols indicate the days of vaginal opening). On the righthand side data are given for all female G. musteloides. Concentrations of oestrogens (b) and progesterone (d) on days before (B), during (days 1 and 2) and after (days 8, 14, 20) the first vaginal opening $(\mathrm{VO})$ are plotted as medians with interquartiles. ( $f$ ) The median distribution of different types of cell in the vaginal smears during the days of the first vaginal opening. (h) The number of animals in which a second spontaneous vaginal opening (SVO) was observed during the mesh-contact phase. 
During the mating phase, oestrus was recorded after 3-13 days in female $C$. aperea, indicating that oestrus is dependent on the cyclic state of the female at the beginning of the experimental stage. In contrast, this individual variation was not observed in female G. musteloides. Oestrus was induced rapidly within 3 days after pairing with a male. This observation is in agreement with findings by Rood and Weir (1970) and Weir $(1971,1973)$ who showed that oestrus was induced in Galea by contact between the sexes.

Male odours and pheromones play an important role in the reproduction of mammals (Parkes and Bruce, 1961; Aron, 1979). The second experimental stage was located in another housing room, in the absence of males to exclude male influences on the oestrous cycle. Under these conditions, eight of nine female $C$. aperea showed a spontaneous vaginal opening between day 15 and day 24 after parturition. Cytological compositions of the vaginal smears confirmed 'vaginal oestrus', and serum hormone concentrations revealed, in at least two experimental females, markedly increased concentrations of oestrogen on day 1 of vaginal opening. Because of relatively large sampling intervals, this short surge of oestrogen may not have been detected in the other females. Thus, a spontaneously occurring oestrus was confirmed in female $C$. aperea and similar cytological and hormonal characteristics were observed as described for the oestrous cycle of the domestic guinea-pig (Selle, 1922; Young, 1937; Silveira and Machado, 1971; Joshi et al., 1973; Garris and Mitchell, 1979; Hammarström et al., 1992). In contrast, no signs of oestrus were observed in the female G. musteloides during the entire separation phase. When this phase was extended to $\geqslant 60$ days and the possible effects of lactation were controlled for, no vaginal openings occurred, as revealed by data from preliminary investigations. This finding is in accordance with those from other studies (Rood and Weir, 1970; Weir, 1971, 1973; Tam, 1973; Norris and Adams, 1979).

During the mesh-contact phase, females were separated from males by a wire mesh, but acoustic, visual and olfactory contact was possible. In female $C$. aperea, the first oestrus was recorded between day 2 and day 20 after the start of the experimental mesh-contact phase and further periods of oestrus recurred spontaneously at 15 day intervals in all females. Determination of hormone concentrations supported these findings of cyclic ovarian activity. However, measured concentrations of steroids may reflect only short periods of the real hormonal patterns; therefore, the true oestrogen or progesterone peaks may not be represented in these data, although parts of the hormone surges may be reflected. In all females, progesterone concentrations were generally low during the periods of oestrus, but increased within a few days to high concentrations and subsequently decreased slowly, reaching basal values shortly before the next oestrus was recorded. This pattern indicates a spontaneously occurring ovulation and subsequent corpus luteum activity in female $C$. aperea (Joshi et al., 1973; Croix and Franchimont, 1975; Blatchley et al., 1976; Hammarström et al., 1992). Thus, the results confirmed an oestrous cycle for the wild cavy (C. aperea) similar to that of the domestic guinea pig (Cavia aperea f. porcellus) with spontaneously occurring periods of oestrus, ovulation and corpus luteum activity. This type of oestrous cycle is typical for most caviomorph rodents (Rood and Weir, 1970; Weir, 1974) and is also relatively common in other mammals.

In all female G. musteloides, contact with a male through a wire mesh was sufficient to induce oestrus within 2-3 days. This finding is contradictory to the conclusions of other studies in which it was argued that only direct physical contact between the sexes could induce oestrus in female G. musteloides (Rood and Weir, 1970; Weir, 1971, 1973). Similar to female $C$. aperea, short surges of oestrogen were detected in at least three experimental female G. musteloides during the first days of oestrus. The patterns of progesterone also differed from those observed in the separation phase and showed similarities to the patterns found in female $C$. aperea, indicating pronounced corpus luteum activity after ovulation. This finding is in contrast to the conclusions of other studies, in which ovulation in Galea was expected to be induced by copulation (Rood and Weir, 1970; Weir, 1971, 1973; Norris and Adams, 1979). Thus, findings from the present study reveal a unique reproductive pattern for the yellow-toothed cavy (Galea musteloides): without contact with males no cyclic activity is evident, but oestrus is induced rapidly by stimuli from the male. During this male-induced oestrus, ovulation occurs without additional stimuli (for example, from copulation) and is followed by spontaneous corpus luteum activity.

The results of the comparative experimental approach used in the present study revealed different types of oestrous cycle in females of the closely related species $C$. aperea and G. musteloides.

Cooper et al. (2000) reported marked differences in sperm morphology and sperm motility in these two species. The polygynous Cavia males produce fewer spermatozoa than the promiscuous Galea males, but the maximum velocity of mature Cavia spermatozoa in vitro is greater than that of Galea spermatozoa. In addition, Cavia spermatozoa are twice the length of those from Galea, they have larger heads and agglutinate into rouleaux. Cooper et al. (2000) suggested that the different post-testicular maturational profiles of sperm motility and morphology of the related species may be explained by the reproductive pattern of the females. In the present study, a spontaneous oestrous cycle of about 15 days was observed in female $C$. aperea, and copulation was permitted only for a limited period at ovulation (Rood and Weir, 1970; Weir, 1974). In contrast, in G. musteloides, oestrus is induced and sperm deposition probably precedes the time of ovulation by several hours. On the basis of these findings, the competitive pressure on Cavia spermatozoa to effect fertilization may have selected for larger and faster spermatozoa and for agglutination to help protect the larger acrosomes. Conversely, the necessary longer transit of Galea spermatozoa in the female reproductive tract may reflect evolutionary pressures that confer stability on the sperm acrosome rather than promotion of sperm motility. 
In conclusion, data from the present study indicate that the reproductive physiology of females (cyclicity versus induced oestrus) might have shaped the divergent evolution of sperm morphology and motility in these two species.

The authors are grateful to $S$. Kaiser for stimulating discussions throughout the study and thank M. Stark for excellent technical assistance in the laboratory. The authors extend their thanks to M. Asher and C. Schmidt for helpful comments on drafts of the manuscript. The experiments were announced to the competent local authority and were approved by the 'Tierschutzbeauftragter' of the University of Münster. The project was supported by the 'Deutsche Forschungsgemeinschaft' (Sa 389/3).

\section{References}

Aron C (1979) Mechanisms of control of the reproductive function by olfactory stimuli in female mammals Physiological Reviews 59 229-284

Blatchley FR, Donovan BT and Ter Haar MB (1976) Plasma progesterone and gonadotrophin levels during the estrous cycle of the guinea-pig Biology of Reproduction 15 29-38

Bronson FH (1985) Mammalian reproduction: an ecological perspective Biology of Reproduction 32 1-26

Carter CS, Getz LL, Gavish L, McDermott JL and Arnold P (1980) Malerelated pheromones and the activation of female reproduction in the prairie vole (Microtus ochrogaster) Biology of Reproduction 23 1038-1045

Clutton-Brock TH and Harvey PH (1978) Mammals, resources and reproductive strategies Nature 273 191-195

Conaway CH (1971) Ecological adaptation and mammalian reproduction Biology of Reproduction 4 239-247

Cooper TG, Weydert S, Yeung C, Künzl C and Sachser N (2000) Maturation of epididymal spermatozoa in the non-domesticated guinea pigs Cavia aperea and Galea musteloides. Journal of Andrology 21 154-163

Croix D and Franchimont P (1975) Changes in the serum levels of the gonadotrophins progesterone and estradiol during the estrous cycle of the guinea pig Neuroendocrinology 19 1-11

Fadem BH (1987) Activation of estrus by pheromones in a marsupial: stimulus control and endocrine factors Biology of Reproduction 36 328-332

Garris DR and Mitchell JA (1979) Intrauterine oxygen tension during the estrous cycle in the guinea pig: its relation to uterine blood volume and plasma estrogen and progesterone levels Biology of Reproduction 21 149-159

Gray GD, Davis HN, Zerylnick M and Dewsbury DA (1974) Oestrus and induced ovulation in montane voles Journal of Reproduction and Fertility 38 193-196

Hammarström M, Ricksten AM and Eneroth P (1992) Reproductive hormone pattern in the female guinea-pig serum during the estrous cycle Scandinavian Journal of Laboratory Animal Science 19 27-32

Hasler MJ and Conaway $\mathbf{C H}$ (1973) The effect of males on the reproductive state of female Microtus ochrogaster. Biology of Reproduction 9 426-436

Hinds LA and Smith MJ (1992) Evidence from plasma progesterone concentrations for male-induced ovulation in the brush-tailed bettong, Bettongia penicillata. Journal of Reproduction and Fertility 95 291-302

Hinds LA, Reader M, Wernberg-Moller S and Saunders NR (1992) Hormonal evidence for induced ovulation in Monodelphis domestica. Journal of Reproduction and Fertility 95 303-312

Joshi HS, Watson DJ and Labhsetwar AP (1973) Ovarian secretion of oestradiol, oestrone, 20-dihydroprogesterone and progesterone during the oestrous cycle of the guinea pig Journal of Reproduction and Fertility 35 177-181

Keil A and Sachser N (1998) Reproductive benefits from female promiscuous mating in a small mammal Ethology 104 897-903

Nelson RJ (2000) An Introduction to Behavioral Endocrinology 2nd Edn, Sinauer Associates, Inc., Sunderland, Massachusetts

Norris LM and Adams CE (1979) The vaginal smear, mating, egg transport and preimplantation development in a wild guinea pig, the cuis (Galea musteloides) Journal of Reproduction and Fertility 55 457-461
Palme R and Möstl E (1994) Biotin-streptavidin enzyme immunoassay for the determination of oestrogens and androgens in boar faeces. In Advances of Steroid Analysis 1993 pp 111-117 Ed. S Görög. Akadémiai Kiadó, Budapest

Parkes AS and Bruce HM (1961) Olfactory stimuli in mammalian reproduction Science 134 1049-1054

Redford KH and Eisenberg JF (1992) Mammals of the Neotropics - The Southern Cone: Chile, Argentinia, Uruguay, Paraguay University of Chicago Press, Chicago, London

Rissman EF, Silveira J and Bronson FH (1988) Patterns of sexual receptivity in the female musk shrew (Suncus murinus) Hormones and Behavior 22 186-193

Rood JP (1972) Ecological and behavioral comparison of the three genera of Argentine cavies Animal Behavior Monographs 5 1-83

Rood JP and Weir BJ (1970) Reproduction in female wild guinea-pigs Journal of Reproduction and Fertility 23 393-409

Sachser N (1998) Of domestic and wild guinea-pigs: studies in sociophysiology, domestication and social evolution Naturwissenschaften 85 $307-317$

Sachser N and Pröve E (1984) Short-term effects of residence on the testosterone response to fighting in alpha male guinea pigs Aggressive Behavior 10 285-292

Sachser N, Schwarz-Weig E, Keil A and Epplen JT (1999) Behavioural strategies, testis size and reproductive success in two caviomorph rodents with different mating systems Behaviour 136 1203-1217

Schwarzenberger F, Tomasova K, Holeckova D, Matern B and Möstl E (1996) Measurement of fecal steroids in the black rhinoceros (Diceros bicornis) using group-specific enzymeimmunoassays for 20-oxopregnanes Zoo Biology 15 159-171

Schwarz-Weig E and Sachser N (1996) Social behaviour, mating system and testes size in cuis (Galea musteloides) Zeitschrift für Säugetierkunde $\mathbf{6 1}$ $25-38$

Selle RM (1922) Changes in the vaginal epithelium of the guinea pig during the oestrous cycle American Journal of Anatomy 30 429-449

Silveira Filho JF and Machado JC (1971) Changes in the vaginal epithelium and smears of the cavy (Cavia aperea aperea) during the estrus cycle and comparative study with the guinea pig Memorias do Instituto Butantan, Sao Paulo 35 63-78

Stockard CR and Papanicolaou GN (1917) The existence of a typical oestrous cycle in the guinea-pig - with a study of its histological and physiological changes American Journal of Anatomy 22 225-283

Sundquist C, Amador AG and Bartke A (1989) Reproduction and fertility in the mink (Mustela vison) Journal of Reproduction and Fertility 85 413-441

Tam WH (1973) Progesterone levels during the oestrous cycle and pregnancy in the cuis, Galea musteloides. Journal of Reproduction and Fertility 35 105-114

Taylor SA, Salo AL and Dewsbury DA (1992) Estrus induction in four species of voles (Microtus) Journal of Comparative Psychology 106 366-373

Weir BJ (1971) The evocation of oestrus in the cuis, Galea musteloides. Journal of Reproduction and Fertility 26 405-408

Weir BJ (1973) The role of the male in the evocation of oestrus in the cuis, Galea musteloides (Rodentia: Hystricomorpha) Journal of Reproduction and Fertility Supplement 19 421-432

Weir BJ (1974) Reproductive characteristics of hystricomorph rodents Symposia of the Zoological Society of London 34 265-301

Weir BJ and Rowlands IW (1973) Reproductive strategies of mammals Annual Review of Ecology and Systematics 4 139-163

Wildt DE, Chan SYW, Seager SWJ and Chakraborty PK (1981) Ovarian activity, circulating hormones and sexual behavior in the cat. I. Relationships during the coitus-induced luteal phase and the estrous period without mating Biology of Reproduction 25 15-28

Young WC (1937) The vaginal smear picture, sexual receptivity and the time of ovulation in the guinea pig Anatomical Record 67 305-325

Received 14 August 2000.

First decision 13 September 2000.

Accepted 19 December 2000. 